\title{
Estimating Potential Nitrogen Mineralisation Using the Solvita Soil Respiration System
}

\author{
Richard L. Haney ${ }^{1}$, Elizabeth B. Haney ${ }^{2 *}$, Douglas R. Smith ${ }^{1}$, Michael J. White ${ }^{1}$ \\ ${ }^{1}$ Grassland, Soil and Water Research Laboratory, Agricultural Research Service, United States Department of \\ Agriculture (USDA-ARS), Temple, TX, USA \\ ${ }^{2}$ Texas Agrilife Research \& Extension Center, Texas A \& M University, Temple, TX, USA \\ Email: "Ihaney@brc.tamus.edu
}

Received 23 November 2015; accepted 18 December 2015; published 23 December 2015

Copyright (C) 2015 by authors and Scientific Research Publishing Inc.

This work is licensed under the Creative Commons Attribution International License (CC BY).

http://creativecommons.org/licenses/by/4.0/

(c) () Open Access

\begin{abstract}
Nitrogen $(\mathrm{N})$ mineralisation contributes considerably to crop growth in fertilized and unfertilized fields. It is useful to be able to assess potential $\mathrm{N}$ mineralisation to increase fertilizer application efficiency, prevent excessive $\mathrm{N}$ runoff, and improve environmental system models. The microbes present in soil mineralize $\mathrm{N}$ based on many factors, including soil temperature and moisture, tillage, and levels of organic $C$ and $N$. The measurement of soil's ability to mineralize $N$ is considered a good indicator of soil quality. Many methods have been developed to estimate $\mathrm{N}$ mineralisation in the laboratory and field. The 7-day anaerobic $\mathrm{N}$ mineralisation method developed in the 1960's is considered reliable and is often used to compare new $\mathrm{N}$-mineralisation testing methods. This study examines the use of soil $\mathrm{CO}_{2}$ evolution as determined using the Solvita Soil Respiration System (Solvita) for estimating $\mathrm{N}$ mineralisation by comparing it directly to the anaerobic $\mathrm{N}$ mineralisation test. Measured $\mathrm{CO}_{2}$ using Solvita was strongly correlated with anaerobic $\mathrm{N}$ mineralisation $\left(r^{2}=0.82\right)$. Results indicate that the Solvita Soil Respiration System can be used to rapidly assess soil respiration and relative $\mathrm{N}$ mineralisation potential in any given soil and is considerably faster and easier to perform in a laboratory setting than the anaerobic $\mathrm{N}$ mineralisation test.
\end{abstract}

\section{Keywords}

Anaerobic N, Nitrogen Mineralisation, Soil Respiration

\section{Introduction}

Nitrogen (N) and phosphorus inputs are said to be the primary nonpoint sources of pollution in many parts of the "Corresponding author.

How to cite this paper: Haney, R.L., Haney, E.B., Smith, D.R. and White, M.J. (2015) Estimating Potential Nitrogen Mineralisation Using the Solvita Soil Respiration System. Open Journal of Soil Science, 5, 319-323.

http://dx.doi.org/10.4236/ojss.2015.512030 
United States [1]. Plants obtain N from fertilizer applications, atmospheric deposition, precipitation, and biological fixation and mineralisation. Fertilizer recommendations are routinely based on the amount $\mathrm{NO}_{3}^{-}$determined during soil testing, negating the contribution of $\mathrm{N}$ due to biological activity and resulting in over application of fertilizer. Long-term use of fertilizer has a negative environmental impact by contributing to excessive $\mathrm{N}$ and P loading in streams, rivers, and ultimately the ocean. It is therefore important to be able to accurately predict $\mathrm{N}$ mineralisation in the environment; however, accurate soil $\mathrm{N}$ mineralisation estimates are difficult to obtain rapidly in the laboratory setting [2].

The mineralisation of soil $\mathrm{N}$ is controlled by microbial activity as they decompose organic material to obtain energy. Microbial activity is dependent upon soil temperature and moisture, agricultural practices, and physical and chemical soil characteristics. Smith and Humfeld [3] observed that during decomposition studies of green manures, bacteria counts trended with $\mathrm{CO}_{2}$ evolution, rising rapidly during the first 4 days and then declining to a constant level. Previously in 1919, Gainey [4] had noticed the parallel formation of $\mathrm{CO}_{2}, \mathrm{NH}_{4}-\mathrm{N}$, and $\mathrm{NO}_{3}-\mathrm{N}$ in soil. Lebedjantzev [5] indicated that drying soil at a low temperature in the laboratory or the field appeared to increase the fertility of the soil. $\mathrm{CO}_{2}$ respiration from soil has been studied for over 90 years as an indicator of the rates of $\mathrm{C}, \mathrm{N}$, or $\mathrm{P}$ mineralisation and ultimately the relative fertility of various soils [4]-[6]. It is now commonly accepted $\mathrm{N}$ mineralisation is a measurement of soil quality [7] that is dependent upon the biogeochemical cycling systems of soils including microbial activity.

The Solvita Soil Respiration System (Solvita) is a new tool to evaluate soil microbial respiration rates in an efficient and cost-effective manner, without the need for reagent handling and long incubation periods. Solvita was designed as a complete procedure to quantify the relative differences between varying types of compost by measuring the amount of $\mathrm{CO}_{2}$ evolved in a short time period [8]. The amount of $\mathrm{CO}_{2}$ evolved is interpreted as an indication of the completeness of active degradation, also called a maturity index. In composts and manures, Solvita has been used in combination with other indices to determine compost maturity and C and N mineralisation (see www.Solvita.com for complete publications list). The Solvita system has also been suggested as a potential tool for assessing $\mathrm{N}$ mineralisation in soils and is currently being utilized by several commercial and government laboratories throughout the United States for this purpose [9]-[11].

There are many published methods for the determination of $\mathrm{N}$ mineralisation including long-term aerobic incubation (3 days and 24 days [12], 41 weeks [13]), 7-day anaerobic incubation [14], in situ field methods [2], and others [15]. These methods are either too time consuming and laborious for commercial labs to perform at a cost effective price or are not adequate for predicting $\mathrm{N}$ mineralisation.

The 7-day anaerobic $\mathrm{N}$ mineralisation method is considered the best biological indicator of potentially available $\mathrm{N}$ and is commonly used to compare new $\mathrm{N}$-mineralisation testing methods [15]. The objective of this study is to apply the Solvita measurement of $\mathrm{CO}_{2}$ in soils to determine $\mathrm{N}$ mineralisation and compare it to the 7-day anaerobic $\mathrm{N}$ mineralisation method developed by Waring and Bremner [14].

\section{Materials and Methods}

A random sub-sampling (207) of soil samples from the contiguous United States and England, UK that were submitted to the United States Department of Agriculture-Agricultural Research Service lab in Temple, TX, from 2010 to 2014 were utilized in this study. Samples were obtained from Texas, Idaho, Maine, West Virginia, Oklahoma, Georgia, and Louisiana. Some samples obtained were not specifically identified when submitted to the laboratory. In addition, soil-testing results from 50 samples provided by an independent private soil-testing lab were utilized, bringing the total number of samples in the study to 257. The locations for the samples provided from the soil-testing lab were not provided. Methods utilized by both labs were identical.

Soil samples were obtained from the top $15 \mathrm{~cm}$ of the soil profile. All soil samples were dried at $50^{\circ} \mathrm{C}$ for $24 \mathrm{~h}$ and ground to pass a 2-mm sieve. Soil organic matter content was determined using loss on ignition [16]. Tengram soil samples were analyzed prior to incubation and extracted with $40 \mathrm{ml}$ of $2 \mathrm{M} \mathrm{KCl}$ to determine initial $\mathrm{NH}_{4}^{+}-\mathrm{N}$ content. Nitrogen mineralisation was determined using the anaerobic incubation test described by Waring and Bremner [14], and equals the $\mathrm{NH}_{4}^{+}-\mathrm{N}$ detected on an OI Analytical RFA after incubation minus the $\mathrm{NH}_{4}^{+}-\mathrm{N}$ initially present in the soil.

The flush of $\mathrm{CO}_{2}$-C following rewetting of dried soil was determined in 40-g subsamples of each soil in 50-ml polypropylene disposable beakers (Fisherbrand Cat. No. 01 - 291 - 10) with four to five 6.35-mm holes drilled in the bottom. A whatman GF/D 4.25-cm glass microfiber filter (Cat No. 1823 - 042) was placed in the bottom of the beaker to prevent soil loss. The beaker and Solvita Soil Respiration paddle were placed in a gas-tight 
250-mL glass jar filled with $20 \mathrm{~mL}$ of water and sealed with a screw-top lid. The glass jar has a convex bottom to allow for drainage. Capillary action was used to rewet soil according to its water holding capability [17]. Soils were incubated at $25^{\circ} \mathrm{C}$ and respired $\mathrm{CO}_{2}$-C was measured after $24 \mathrm{~h}$. The quantity of $\mathrm{CO}_{2}$-C released was determined using a digital-color reader (DCR) as described by Haney [9]. The Solvita system for estimating the flush of $\mathrm{CO}_{2}$-C following rewetting of dried soil has been shown to be highly correlated with the commonly used titration method and $\mathrm{CO}_{2}$-C IRGA method [9]. SigmaStat imbedded in SigmaPlot ver. 12.2 was used for linear regression analysis [18].

\section{Results and Discussion}

The range in soil organic matter for the soil samples was $0.8 \%$ to $7.5 \%$ (Figure 1). The Solvita results in mg C per kg soil are highly correlated with anaerobic 7-day $\mathrm{N}$ mineralisation values (Figure 2). These data correspond with findings by [12], [19] [20] that the flush of $\mathrm{CO}_{2}$ following rewetting dried soil is strongly correlated with potential $\mathrm{N}$ mineralisation. While both the anaerobic 7-day mineralisation test and the Solvita test do not require preliminary analysis to determine the amount of water added to each soil, the 7-day $\mathrm{N}$ mineralisation test does require preliminary $\mathrm{NH}_{4}^{+}-\mathrm{N}$ determination and Solvita does not. In addition, the Solvita test can be performed without the use of reagents to extract $\mathrm{NH}_{4}^{+}-\mathrm{N}$, laboratory steam distillation and titration (which introduces considerable human error), and can be completed in just over $24 \mathrm{~h}$ versus 7 days. Furthermore, Wienhold et al. [2] indicate that anaerobic $\mathrm{N}$ mineralisation underestimates field $\mathrm{N}$ mineralisation when compared to aerobic $\mathrm{N}$ mineralisation. The ability to rapidly assess potential $\mathrm{N}$ mineralisation with a simple test should be highly attractive to commercial soil testing labs.

One possible limitation to predicting $\mathrm{N}$ mineralisation from the anaerobic test or directly from Solvita is that, regardless of the respiration number, you cannot predict when a given soil is in a state of $\mathrm{N}$ immobilization. Only in situ field mineralisation tests, which are not practical at a large spatial or commercial laboratory temporal scale, would possibly be able to predict field conditions under any given time. The relationship between Solvita and mineralisation will be sufficient to predict field $\mathrm{N}$ mineralisation.

\section{Conclusions}

Based on the strong correlation between the 7-day N mineralisation test and Solvita test results, across a diverse set of soils, it would be justified to utilize Solvita to predict $\mathrm{N}$ mineralisation using the equation below $\left(\mathrm{r}^{2}=\right.$ 0.82 ):

$$
\mathrm{N} \text { mineralised (mg } \mathrm{N} \text { per } \mathrm{kg} \text { soil })=1.23 \times \text { Solvia respiration result }-9.7
$$

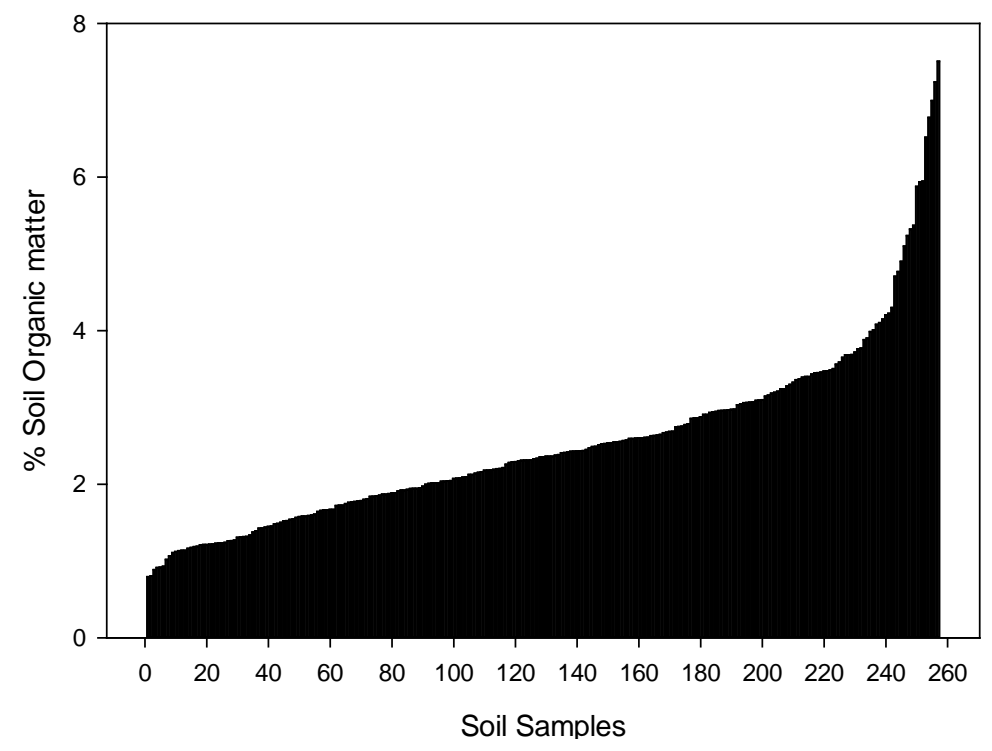

Figure 1. Range in soil organic matter (\%) in 257 soil samples analyzed. 


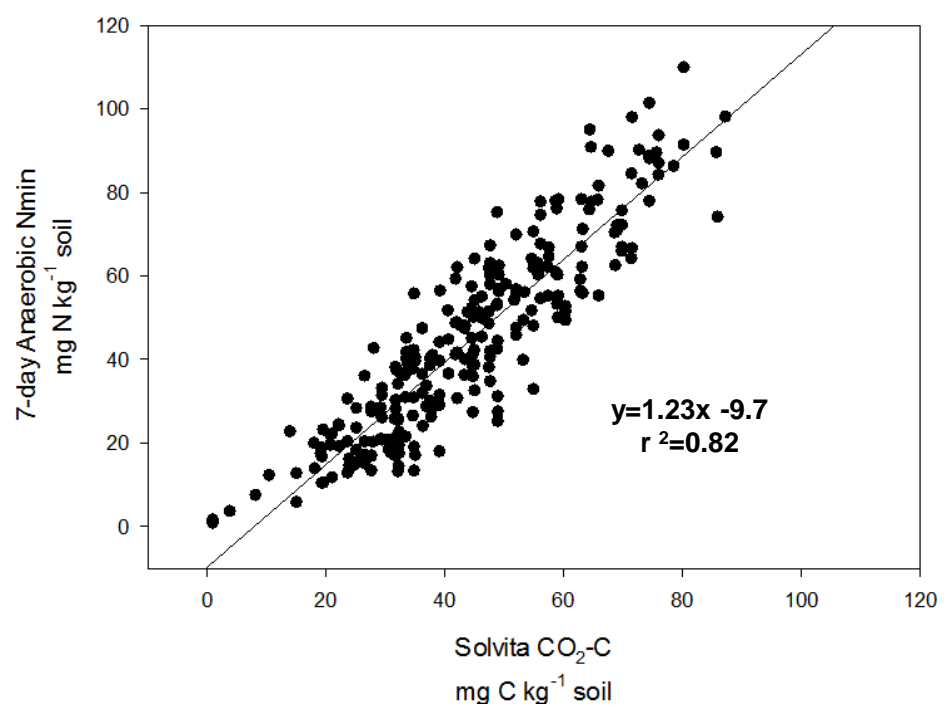

Figure 2. Solvita 1-day C vs. 7-day anaerobic N mineralisation from 257 soil samples.

Solvita can be used to rapidly assess soil respiration and relative $\mathrm{N}$ mineralisation potential in any given soil under laboratory conditions. The advantage to utilizing the Solvita test is that: the test only takes 1 day versus 7 days to perform and the analytical equipment is less expensive (Solvita machine versus colorimetric analysis). These results are novel in that Solvita is the first test that uses soil-microbe respiration to estimate $\mathrm{N}$ mineralization which is, in fact, microbially driven.

\section{References}

[1] Jha, M.K., Gassman, P.W. and Panagopoulos, Y. (2015) Regional Changes in Nitrate Loadings in the Upper Mississippi River Basin under Predicted Mid-Century Climate. Regional Environmental Change, 15, 449-460. http://dx.doi.org/10.1007/s10113-013-0539-y

[2] Wienhold, B.J. (2007) Comparison of Laboratory Methods and an in Situ Method for Estimating Nitrogen Mineralisation in an Irrigated Silt-Loam Soil. Communications in Soil Science and Plant Analysis, 38, 1721-1732. http://dx.doi.org/10.1080/00103620701435498

[3] Smith, N.R. and Humfeld, H. (1931) The Decomposition of Green Manures Grown on a Soil and Turned under Compared to the Decomposition of Green Manures Added to a Fallow Soil. Journal of Agricultural Research, 43, 715-731.

[4] Gainey, P.L. (1919) Parallel Formation of Carbon Dioxide, Ammonia, and Nitrate in Soil. Soil Science, 7, 293-311. http://dx.doi.org/10.1097/00010694-191904000-00007

[5] Lebedjantzev, A.N. (1924) Drying of Soil, as One of the Natural Factors in Maintaining Soil Fertility. Soil Science, 18, 419-447. http://dx.doi.org/10.1097/00010694-192412000-00001

[6] Birch, H.F. (1960) Nitrification in Soils after Different Periods of Dryness. Plant Soil, 7, 81-96.

[7] Deenik, J. (2006) Nitrogen Mineralization Potential in Important Agricultural Soils of Hawai'I. University of Hawaii, Honolulu (HI), 5 p. (Soil and Crop Management; SCM-15).

[8] Doran, J., Kettler T. and Tsivou M. (1997) Field and Laboratory Solvita Soil Test Evaluation. Manuscript University of Nebraska USDA-ARS, Lincoln.

[9] Haney, R., Brinton W. and Evans E. (2008) Estimating Soil Carbon, Nitrogen, and Phosphorus Mineralization from Short-Term $\mathrm{CO}_{2}$ Respiration. Communications in Soil Science and Plant Analysis, 39, 2706-2720. http://dx.doi.org/10.1080/00103620802358862

[10] Jin, V.L., Johnson M-V.V., Haney R.L. and Arnold J.G. (2011) Potential Carbon and Nitrogen Mineralization in Soils from a Perennial Forage Production System Amended with Class B Biosolids. Agriculture, Ecosystems \& Environment, 141, 461-465. http://dx.doi.org/10.1016/j.agee.2011.03.016

[11] Harmel, R.D. and Haney, R.L. (2013) Initial Field Evaluation of the Agro-Economic Effects of Determining Nitrogen Fertilizer Rates with a Recently-Developed Soil Test Methodology. Open Journal of Soil Science, 3, 91-99. http://dx.doi.org/10.4236/ojss.2013.32010 
[12] Franzluebbers, A.J., Haney, R.L., Honeycutt, C.W., Schomberg, H.H. and Hons, F.M. (2000) Flush of Carbon Dioxide Following Rewetting of Dried Soil Relates to Active Organic Pools. Soil Science Society of America Journal, 64, 613623. http://dx.doi.org/10.2136/sssaj2000.642613x

[13] Wang, W.J., Smith, C.J. and Chen, D. (2003) Towards a Standardized Procedure for Determining the Potentially Mineralizable Nitrogen of Soil. Biology and Fertility of Soils, 37, 362-374.

[14] Waring, S.A. and Bremner, J.M. (1964) Ammonium Production in Soil under Water-Logged Conditions as an Index of Nitrogen Availability. Nature, 201, 951-952. http://dx.doi.org/10.1038/201951a0

[15] Schomberg, H.H., Weitholter, S., Griffin, T.S., Reeves, D.W., Cabrera, M.L., Fisher, D.S., Endale, D.M., Novak, J.M., Balkcom, K.S., Raper, R.L., Kitchen, N.R., Locke, M.A., et al. (2009) Assessing Indices for Predicting Potential Nitrogen Mineralization in Soils under Different Management Systems. Soil Science Society of America Journal, 73, 15751586. http://dx.doi.org/10.2136/sssaj2008.0303

[16] Schulte, E.E. and Hopkins, B.G. (1996) Estimation of Organic Matter by Weight Loss-on-Ignition. In: Magdoff, F.R., et al., Eds., Soil Organic Matter: Analysis and Interpretation, SSSA Special Publication Number 46, SSSA, Madison, 21-31.

[17] Haney, R.L. and Haney, E.B. (2010) Simple and Rapid Laboratory Method for Rewetting Dry Soil for Incubations. Communications in Soil and Plant Analysis, 41, 1493-1501. http://dx.doi.org/10.1080/00103624.2010.482171

[18] Systat Software, Inc. (2012) SigmaPlot for Windows, Version 12.5, Germany.

[19] Franzluebbers, A.J. and Haney, R.L. (2006) Flush of $\mathrm{CO}_{2}$ as a Soil Biological Quality Indicator. Proceedings of the 17th Conference of the International Soil Tillage Research Organization (CD-ROM), Kiel, 3 August-26 September 2006, 736-740.

[20] Haney, R.L., Franzluebbers, A.J., Jin, V.L., Johnson, M.-V., Haney, E.B., White, M.J. and Harmel, R.D. (2012) Soil Organic C:N vs. Water-Extractable Organic C:N. Open Journal of Soil Science, 2, 269-274. http://dx.doi.org/10.4236/ojss.2012.23032 